\title{
Photoinduced 3D Ordering and Patterning of Microphase Separated Nanostructure in Polystyrene-Based Block Copolymer
}

Yuichi Morikawa, Takeshi Kondo, Shusaku Nagano and Takahiro Seki*

Department of Molecular Design and Engineering, Graduate School of Engineering, Nagoya University, Chikusa, Nagoya, 464-8603, Japan

\section{Supporting information}

\section{Synthesis of diblock copolymer}

\subsection{Materials}

$N$, $N$ '-Dimethyl formamide (DMF) as solvent was dehydrated by distillation from calcium hydride. Anisole and tetrahhydrofurane (THF) as solvents was distilled from sodium with benzophenone. Styrene was purified by distillation to remove inhibitor before use. Catalyst $\mathrm{CuBr}$ (Kanto Chem. Co., Japan) was washed with acetic acid containing a drop of HCl solution and diethyl ether for several times, and dried in vacuum. Other compounds were used without further purification.

\subsection{Preparation of Macroinitiator Polystyrene-Br (PS-Br)}
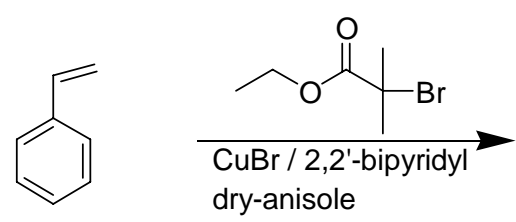<smiles>CCOC(=O)C(C)(C)CC(Br)c1ccccc1</smiles> 
A flask was charged with $7.17 \mathrm{mg}$ of $\mathrm{CuBr}$, degassed and filled with $\mathrm{N}_{2}$ gas. $3.12 \mathrm{~g}$ of styrene, $9.75 \mathrm{mg}$ of 2-bromoisobutyric acid and $78.1 \mathrm{mg}$ of 2,2'-bipyridyl in $1 \mathrm{ml}$ of anisole were degassed, filled with $\mathrm{N}_{2}$ gas and added through a syringe. The mixture was degassed by freeze-pump-thaw procedure and sealed under vacuum. The flask was placed in oil bath at $110{ }^{\circ} \mathrm{C}$ for $11 \mathrm{~h}$. The reaction mixture was dissolved in THF and passed through alumina column to remove Cu catalyst. After being concentrated, The THF solution was poured to methanol to remove styrene monomer. The final product was dried under vacuum. Yield: $350 \mathrm{mg}(11.2 \%) . M_{\mathrm{n}}=8000$ and $M_{\mathrm{w}} / M_{\mathrm{n}}=1.05$ (evaluated by Gel Permeation Chromatography).

\subsection{Preparation of Az monomer}
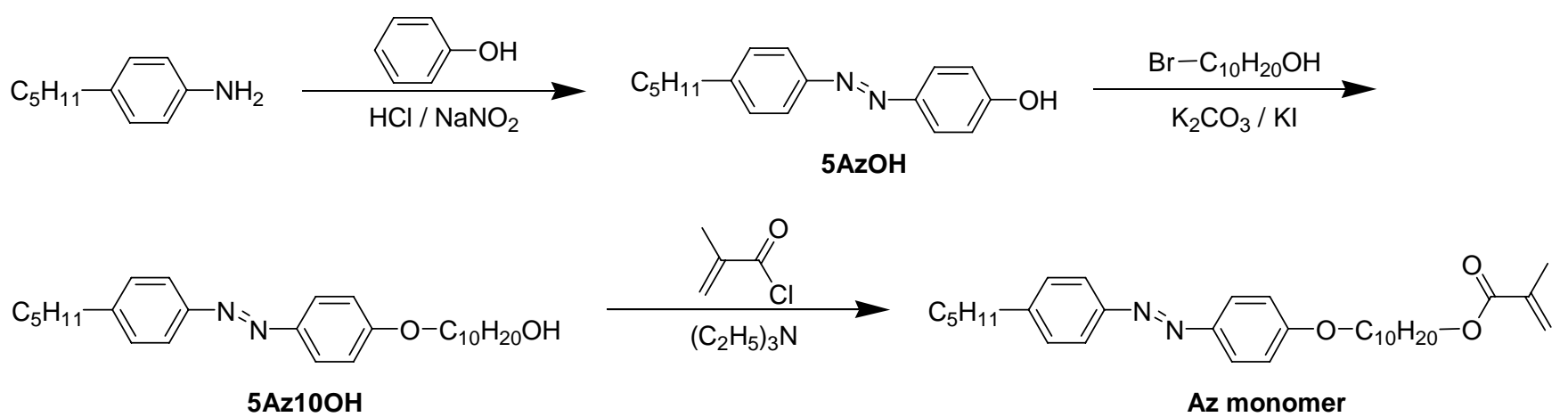

The synthesis of Az monomer was performed according to the above scheme.

\subsubsection{Preparation of 4-[(4'-Pentylphenyl) azo] phenol (5AzOH)}

4-Pentylaniline (25 g, $153 \mathrm{mmol}$ ) was dissolved in a mixture of concentrated hydrochloric acid $(25 \mathrm{~mL})$ and water $(100 \mathrm{~mL})$. Sodium nitrate $(13.2 \mathrm{~g}, 191 \mathrm{mmol})$ in water $(80 \mathrm{~mL})$ was added dropwise to the above solution at $5{ }^{\circ} \mathrm{C}$. An aqueous solution $(800 \mathrm{~mL})$ dissolving phenol $(17.6 \mathrm{~g}$, $187 \mathrm{mmol}$ ) and sodium hydroxide (9.42 g, $235 \mathrm{mmol}$ ) was then added dropwise under stirring. The 
solution was stirred for $2 \mathrm{~h}$ at $5^{\circ} \mathrm{C}$ and $3 \mathrm{~h}$ at room temperature. After this solution was neutralized with a diluted hydrochloric acid aqueous solution, the precipitate was filtered off and dissolved in ethyl acetate. The solution was washed with water, sodium bicarbonate aqueous solution and water and $\mathrm{NaCl}$ aqueous solution, and then, dried over anhydrous magnesium sulfate. The precipitate was recrystallized from hexane twice to give yellow platelet crystals.

Yield: 24.9 g (60.6 \%)

\subsubsection{4-(10-Hydroxydecyloxy)-4'-pentylazobenzene (5Az10OH)}

Potassium carbonate (25.7 g, $186 \mathrm{mmol}$ ) and catalytic amount of potassium iodide were added to $5 \mathrm{AzOH}$ (10.0 g, $37.3 \mathrm{mmol})$ in dry DMF (90ml), and then mixture was stiired for $1 \mathrm{~h}$ at $60{ }^{\circ} \mathrm{C} .10$-Bromodecanol (15.9 $\left.\mathrm{g}, 67.1 \mathrm{mmol}\right)$ in dry DMF $(10 \mathrm{ml})$ was added dropwise to the solution. The solution was stirred for $4 \mathrm{~h}$ at $60{ }^{\circ} \mathrm{C}$. The reaction mixture was washed with water, sodium bicarbonate aqueous solution and $\mathrm{NaCl}$ aqueous solution, and then, dried over anhydrous magnesium sulfate. The solution was evaporated and separated out a solid. This product was recrystallized from methanol to give yellow solid.

Yield: 15.4 g (81.1\%).

\subsubsection{4-(10-Methacryloydecyloxy)-4'-pentylazobenzene (Az monomer)}

Trietylamine (7.16 g, $70.8 \mathrm{mmol})$ was added to 5Az10OH (15.0 g, $35.4 \mathrm{mmol})$ in dry THF solution. A dry THF solution of methacryloyl chloride (7.36 g, $70.8 \mathrm{mmol}$ ) was added dropwise to the solution at $0{ }^{\circ} \mathrm{C}$. The mixture was stirred for $30 \mathrm{~min}$ at $0{ }^{\circ} \mathrm{C}$ and $12 \mathrm{~h}$ at room temperature. The 
reaction mixture was evaporated, and chloroform was added. The solution was washed with water, sodium bicarbonate aqueous solution and $\mathrm{NaCl}$ aqueous solution, and then, dried over anhydrous magnesium sulfate. The solvent was evaporated and the residue was recrystallized from methanol. Yellow solid was obtained.

Yield: 10.4 g (60.0 \%).

\subsection{Preparation of Az-containing diblock copolymer $\left(p\left(S_{x}-A z_{y}\right)\right)$}
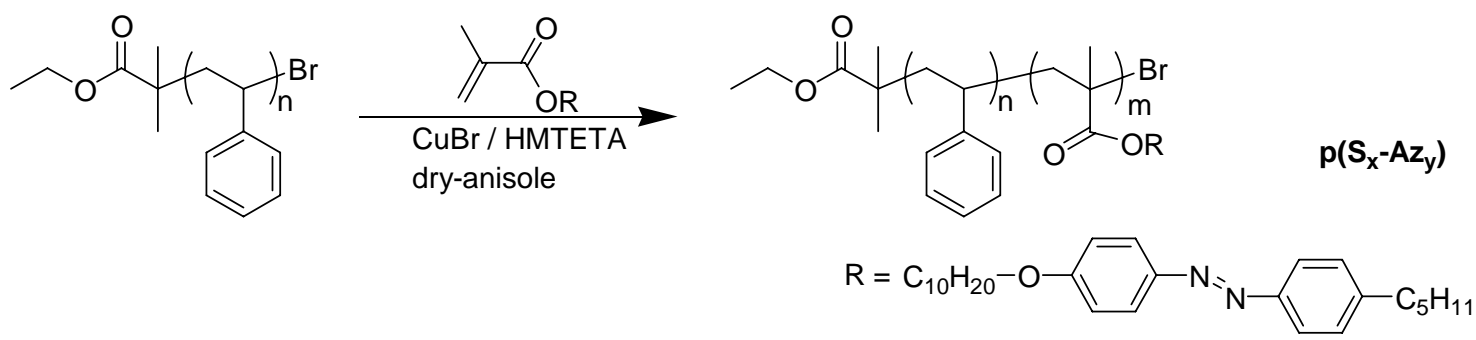

A $10 \mathrm{ml}$ ample tube was charged with $37.6 \mathrm{mg}$ of PS-Br, $399 \mathrm{mg}$ of Az monomer, $8.99 \mathrm{mg}$ of HMTETA and $1 \mathrm{ml}$ of THF. After several freeze-pump-thaw cycles, $5.59 \mathrm{mg}$ of $\mathrm{CuBr}$ was immediately inserted in the ample tube. The mixture was degassed by freeze-pump-thaw procedure and sealed under vacuum. The flask was placed in $70{ }^{\circ} \mathrm{C}$ oil bath for $17 \mathrm{~h}$. The solution was passed through alumina column with chloroform. The solution was concentrated and precipitated in hexane, methanol and finally in hot hexane $\left(60{ }^{\circ} \mathrm{C}\right)$. The precipitation process in each solvent was repeated twice, respectively. The final product was dried under vacuum. Yield: $70 \mathrm{mg}(16.0 \%) . M_{\mathrm{n}}=77000$ and $M_{\mathrm{w}} / M_{\mathrm{n}}=1.21$ (GPC, Figure S1). The ${ }^{1} \mathrm{NMR}$ chart is shown in Figure S2. Thermal phase properties for Az polymer block: $\mathrm{Sm}_{\mathrm{X}}-90{ }^{\circ} \mathrm{C}-\mathrm{Sm}_{\mathrm{A}}-118{ }^{\circ} \mathrm{C}-\mathrm{I}, \mathrm{T}_{\mathrm{g}}$ of polystyrene $=102{ }^{\circ} \mathrm{C}$ (DSC chart is indicated in Figure S3). 


\section{Characterizations}

Molecular weight and polydispersity were measured by gel permeation chromatography (GPC) using a liquid chromatograph (Shodex UV-41) with an appropriate combination of columns (Shodex KF-803L and Shodex KF-805L). THF was used as eluent, and polystyrene standards were used for calibration. ${ }^{1} \mathrm{H}-\mathrm{NMR}$ spectrum was recorded on a JEOL 270GXS instrument spectrometer (270 MHz). Phase transition temperatures were measured with Seiko Instrument DSC6200/EXSTAR6000 (heating and cooling rates: $10{ }^{\circ} \mathrm{C} / \mathrm{min}$ ). 


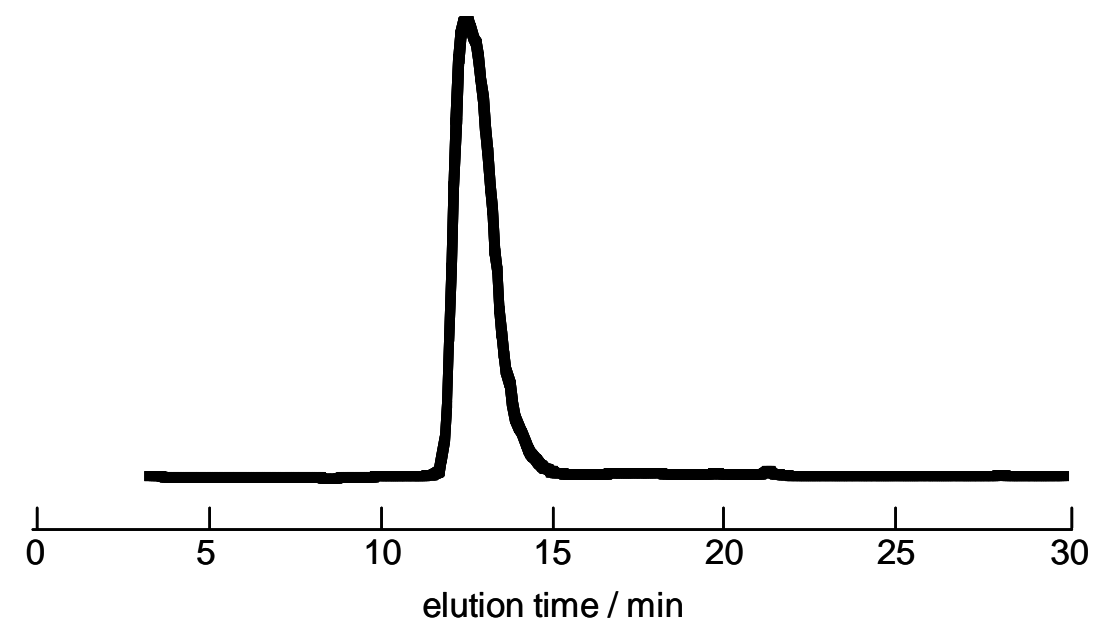

Figure S1. GPC chart of $\mathrm{p}\left(\mathrm{S}_{76}-\mathrm{Az}_{140}\right)$. 

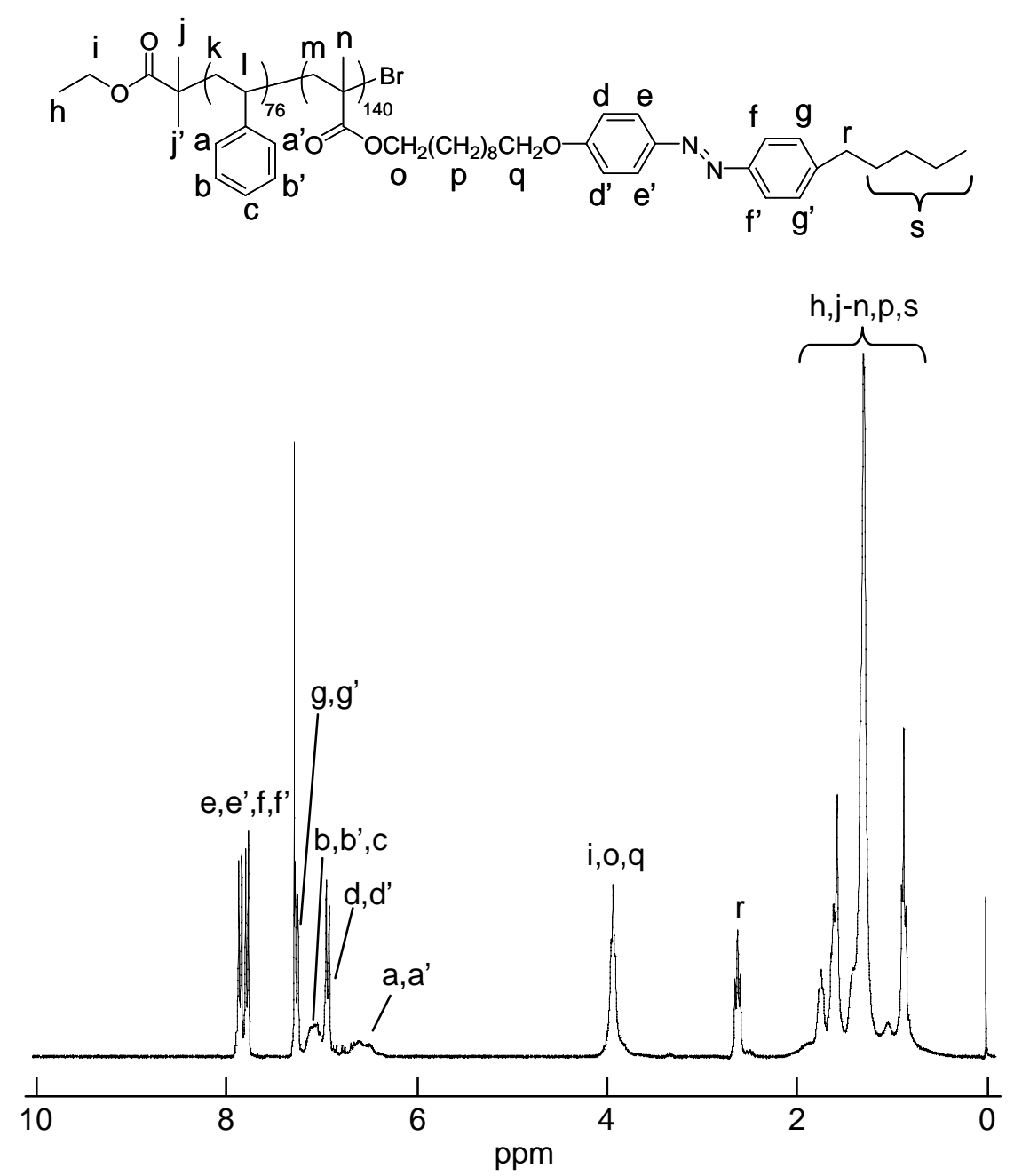

Figure S2. ${ }^{1} \mathrm{H}-\mathrm{NMR}$ spectrum of $\mathrm{p}\left(\mathrm{S}_{76}-\mathrm{Az}_{140}\right)$. 


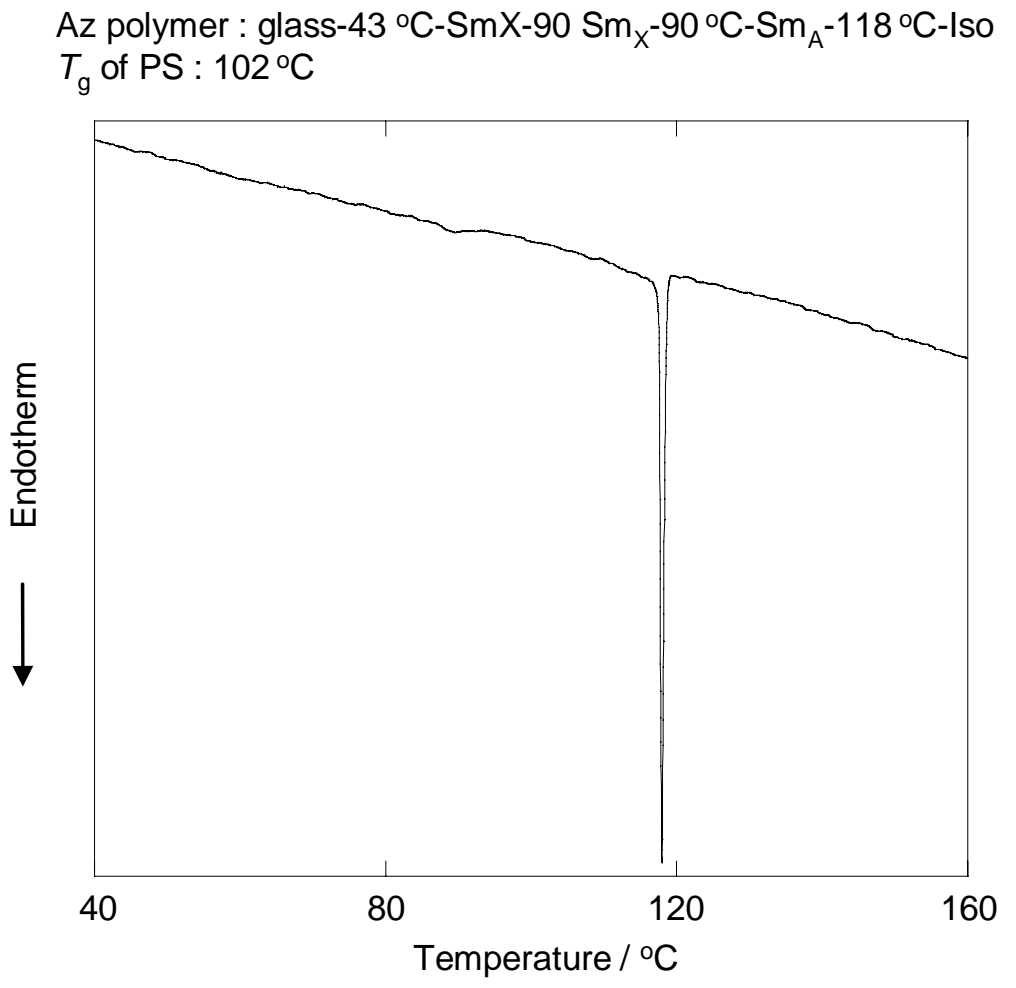

Figure S3. DSC chart of the $\mathrm{p}\left(\mathrm{S}_{76}-\mathrm{Az}_{140}\right)$ in a heating process. 